\title{
The standardization and certification procedures of cryogenic equipment in Kazakhstan
}

\author{
A. Shinbayeva, A. Drobyshev, and N. Drobyshev \\ Al-Farabi Kazakh National University, Almaty 050038, Kazakhstan \\ E-mail: shinbayeva_a@hotmail.com
}

Received February 21, 2015, published online May 25, 2015

\begin{abstract}
The complex of procedures on stepwise carrying out actions of standardization and certification of liquid nitrogen, argon and oxygen gasificator G-200 is considered. In the process of organization of standardization and certification procedures the set of regulatory documents was developed that allow starting small-scale production of gasificators in Kazakhstan. Thus the emphasis on the potential incorporation of the requirements of such documents is placed from the Eurasian Economic Union.
\end{abstract}

PACS: $07.20 . M c$ Cryogenics; refrigerators, low-temperature detectors, and other low-temperature equipment; 06.20.fb Standards and calibration.

Keywords: liquid nitrogen, gasification, standardization, certification.

\section{Introduction}

Recently cryogenic technologies find more and more extensive use in various directions of industrial activity [1-3]. The employment of these technologies in the construction industry, food and oil industry, medicine, cosmetology, mineral processing and agricultural products emphasizes their functional value. At the same time, adoption and employment of innovative cryogenic technologies makes it relevant to the solution of one of the most important problems the organization of standardization and certification procedures. Now in connection with this the question of complex development methods on carrying out procedures of unification on the basis of the existing regulatory documents raises. Thus the purpose of implementation of progressive, improved procedures of standardization is shortterm identification of quality attributes, compliance with the requirements and the consumer's conditions.

Laboratory of cryophysics and cryotechnology at Al-Farabi Kazakh National University over the last 10-15 years actively has been engaged in development and manufacture of low-temperature equipment. In particular, the lowtemperature equipment for gasification of the liquefied gases, such as nitrogen, argon, oxygen (G-200 gasificator) is made, the design is developed and the prototype of the mobile low-temperature thermostabilizer is made, the set of actions for production of the line for low-temperature processing of agricultural raw materials and food products
(Cryoline-kz) is held. With increasing sales market and organization of serial production this type of equipment it is necessary of legislative and regulatory confirmation of compliance to requirements of technical regulations and to provisions of the national standards. Existence of normative documents is an essential prerequisite for increasing sales volume and expansion of the range of provided services. Considering innovation of the introduced cryogenic technologies in Kazakhstan becomes clear that each of them demands special approach when developing standard documentation.

\section{Results and discussion}

In this article the set of procedures of stepwise carrying out actions standardization and certification of liquid nitrogen, argon and oxygen gasificator G-200 which designed and manufactured in the laboratory is considered.

Step 1. Development of technical specifications and description of functional principle of the gasificator G-200 (Fig. 1). The gasificator G-200 refers to cold cryogenic gasificators and is designed for storage and gasification of liquid technical gases and distribution of gaseous product to the consumer. Important feature of the gasificators is possibility of automatic maintenance of predetermined pressure and flow rate. The gasificator consists of a cryogenic tank, consisting of an internal vessel (reservoir) and a casing with effective layered and vacuum thermal insulation, a valve rack, atmospheric evaporators for gasification 


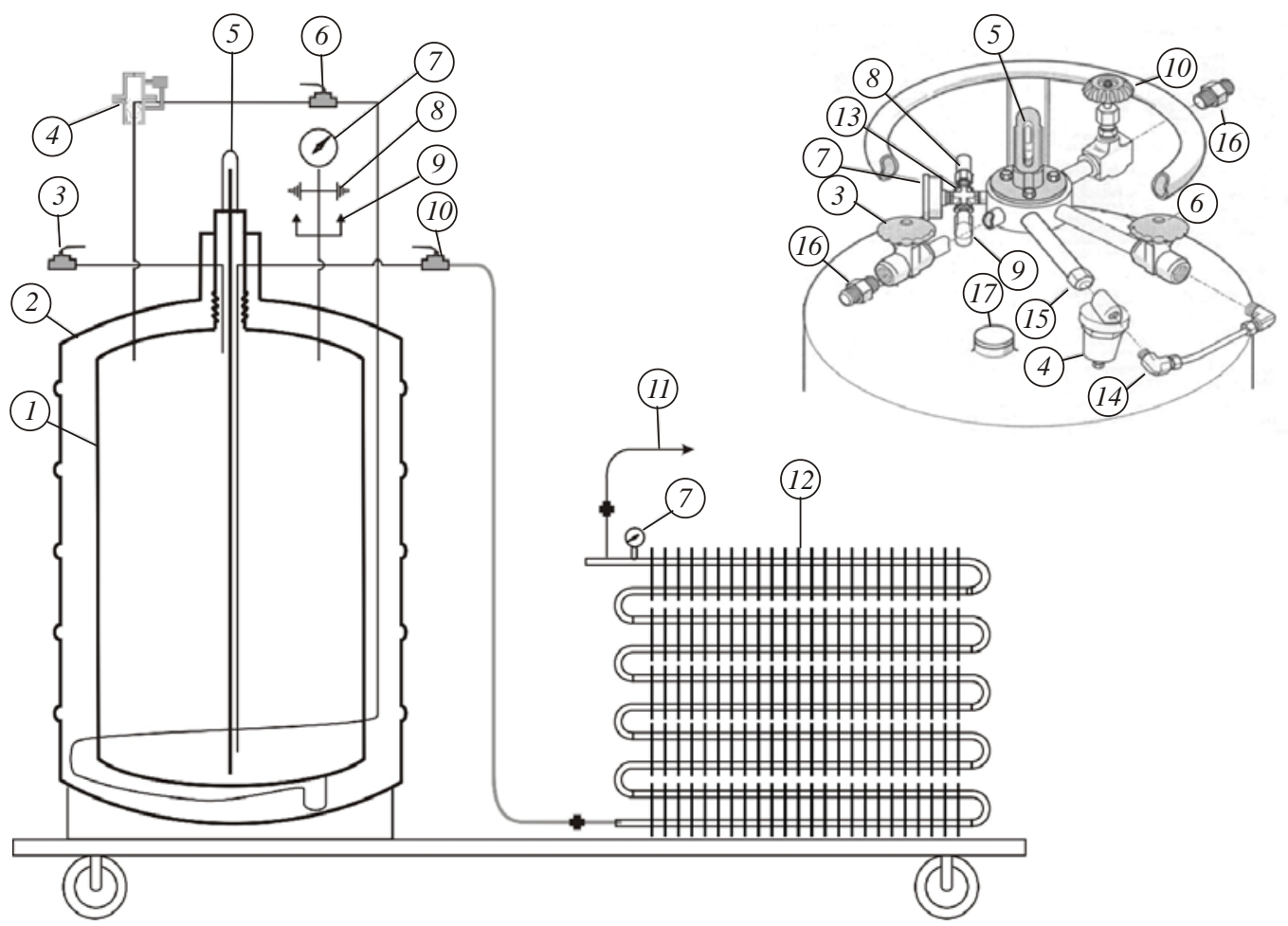

Fig. 1. The construction of gasificator G-200; inner vessel (1), outer casing (2), purge valve (3), pressure regulator (4), level indicator (5), valve of regulator (6), manometer (7), safety valve (8), burst valve (9), refueling and dispensing valve (10), gas make (11), evaporator (12), crosspiece (13), heater (14), pipeline of regulator (15), adapter (16) vacuum fitting (17), coil pressurization (18).

of the liquefied gas (including for pressurization of the tank), reinforcing steel, control devices, protective equipment and pipelines.

The functional principle of the gasificator is the coordinated work of its main components - the vessel for cryoliquid storage and the productional evaporator. As the temperature of liquid nitrogen boiling $(T=76 \mathrm{~K})$ with an atmospheric pressure is much lower than room temperature, process of pressure increase in a vessel is carried out by heat supply to liquid for what the evaporator is also used. Regulating a heat flow or amount of incoming liquid nitrogen in the evaporator it is possible to set the necessary operating conditions, both for pressure and for flow rate of liquid or gaseous nitrogen. The Table 1 below shows the main technical characteristics of the gasificator G-200.

Step 2. The conformity assessment procedure is applied at conformity assessment of products or services (in the form of the declaration about the conformity or the issuance of the conformity certificate) to the requirements established by regulations, standards. The conformity assessment procedure is applied at mandatory and voluntary conformity assessment. Conformity assessment procedures are carried out only by certification bodies and the test laboratories, accredited on the right of carrying out such works in the field of conformity assessment. The expenses associated with work are paid for conformity assessment by the app- licant, regardless of the results, on the basis of the contract. Conformity certificates of foreign countries, end-item test sheet, conformity marks are recognized in accordance with international treaties. The recognition of foreign documents in the field of conformity assessment is carried in accordance with the established procedure by authorized body in the field of technical regulation. The general requirements to conformity assessment procedures, consider requirements of the documents of the International Organization for Standardization and the International Electrotechnical Commission [4-9].

Table 1. The main technical characteristics of the gasificator G-200

\begin{tabular}{l|c}
\hline \hline \multicolumn{1}{c|}{ Specification } & G-200 \\
\hline \hline Operational pressure, $\mathrm{MPa}$ & 1.2 \\
Operational temperature, ${ }^{\circ} \mathrm{C}$ & -196 \\
Pressure of hydraulic test, $\mathrm{MPa}$ & 2.8 \\
Pressure of leak test, $\mathrm{MPa}$ & 1.4 \\
Geometric volume, $\mathrm{L}$ & 200 \\
Nominal volume, $\mathrm{L}$ & 200 \\
Allowable corrosion, mm & 0 \\
Substance & The liquefied nitrogen, \\
& oxygen and argon \\
Statistical evaporation rate, \%/d & $\mathrm{LO}_{2} \leq 1.4, \mathrm{LN}_{2} \leq 2.2$, \\
& LAr $\leq 1.5$ \\
\hline \hline
\end{tabular}


Authorized bodies operating the certification at the Republic of Kazakhstan are:

1. The authorized body on standardization, metrology and certification (Committee on Standardization, Metrology and Certification of the Republic of Kazakhstan of Energy, Industry and Trade Ministry of the Republic of Kazakhstan (National Standard) National Center for Expertise and Certification).

2. Accredited bodies on the certification of products, processes, services.

3. Accredited testing laboratories (centers).

4. Accredited organizations on providing the consulting services in the field of accreditation.

5. Experts are certification auditors.

Procedure of certification is a written acknowledgement by authorized body that the equipment confirm to the requirements, established in normative documents (National Standard) and consists of the following actions:

1. Submission of an application by the applicant to the certification body. If there are several certification bodies of this equipment, the applicant may submit the application to any of them, or if at the time of the application the certification body of this equipment is not exist, the application is forwarded to the National Standard of the Republic of Kazakhstan.

2. Directing the decision based on the results of application consideration to the applicant. This decision is sent to the applicant at 2-week period.

3. Registration of the contract between the applicant and certification body for procedure of the equipment certification. The executed contract is directed to the applicant at a 2-week period in 2 copies.

4. The selection, identification of samples of the claimed equipment and their representation to the test laboratory (center). Selection is carried out by the certification body on a contract basis. The selection can be carried out by the applicant and by the appointment of a competent committee consisting of at least 3 people from among representatives of the uninterested organizations.

5. In necessary cases, the certification body may designate the sampling to the accredited testing commission.

6. The test laboratory (center) carries out the agreed with the certification body deadlines of testing of the claimed equipment samples and sends its results issued in the form of a protocol to the certification body.

7. The analysis of the obtained results and decision making on possibility of issue of the conformity certificate.

8. In case of negative test results, at least on one of the indicators, tests with purpose of certification are terminated. The issuance of the conformity certificate and its registration in the State Register of the Republic of Kazakhstan. At positive results of the performed works provided by the scheme of the declared equipment, the certification body makes out the Certificate of Compliance. This certificate may have an application that contains a list of the equip- ment on which its action extends. Validity period of the Certificate is set by the certification body taking into account the specifics of the equipment.

9. Marking of the certified equipment with a mark of conformity. Marking of the equipment with the mark of conformity is carried out by the manufacturer in the ways providing the clear image, environmental sturdiness, durability, etc. The way and the place of drawing is defined by the certification body.

\section{Conclusions}

In the organization process of standardization and certification procedures the following main results were reached:

1. Maintenance instructions of the G-200 gasificator are developed and approved. The product code under Commodity Nomenclature for Foreign Economic Activities of Custom Union FEACN CU is appropriated as 7311009100 Vessels for compressed or liquefied gas, from ferrous materials: - other with the capacity: - less than 1000 liters.

2. The certificate of conformity №KZ.7500525.05.01. 63266 registered in the State Register of the Republic of Kazakhstan was issued. The company standard 55816-1910 GE-01-2013 on the gasificator of liquid nitrogen, argon and oxygen (G-200) is developed.

3. The presence of these regulatory documents is the basis for creation of the technological line with a serial production of competitive products. Implemented gasificator conforms to requirements of the company standard taking into account requirements of the Technical Regulations "Requirements to safety of the equipment working under pressure". Production of the gasificator is carried out according to the design and technological documentation approved in accordance with the established procedure.

Currently, the scope of these regulatory documents is spread only on Kazakhstan territory. Due to the signing of the contract on creation of the Customs Union of Belarus, Kazakhstan, Russia becomes actual creation of unified regulatory base. One of the mechanisms of creation such base is formation of technical committees for the participating countries. At the moment the Laboratory of cryophysics and cryotechnologies is a member of the International Technical Committee TC 114 "Cryogenic and oxygen equipment". Thus, a perspective task of the next stage is the development of unified regulatory documents for the countries of the Customs Union in the area of standardization and certification of cryogenic and oxygen equipment.

1. A.M. Arkharov, I.V. Marfenina, and Ye.I. Mikulin, Cryogenic Systems, Bauman Moscow State University Press, Moscow (2000).

2. R.F. Barron, Cryogenic Systems, Oxford University Press, London (1985).

3. V.P. Beliakov, Cryogenic Engineering and Technologies, Energoizdat, Moscow (1982). 
4. Law of the Republic of Kazakhstan dated 16.07.1999 № 434-1 “About Certification”.

5. Standard of the Republic of Kazakhstan ST RK 1.5-2008 "General Requirements for the Construction, Presentation, Design and Maintenance of Standards”.

6. Standard of the Republic of Kazakhstan ST RK 1.2-2008 "The Order of Development of National Standards and Standards Organizations”.
7. Technical Regulations of the Republic of Kazakhstan "The Conformity Assessment Procedure".

8. National Standard of the Russian Federation GOST R 1.1-2005 "Technical Committees on Standardization".

9. Rules on Interstate Standardization PMG 02-93 "Model Regulations on the Interstate Technical Committees on Standardization”. 